\title{
アルゴン送気溶融法による鉄鋼 および合金鉄中酸素の定量法*
}

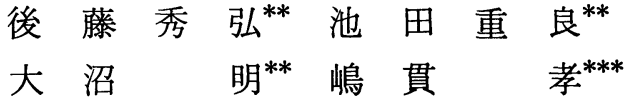

Hidehiro Goto, Shigero Ikeda, Akira Onuma and Takashi Shimanuki : Determination of Oxygen in Iron, Steel and Ferrous Alloys by the Argon Gas Carrier Fusion Method. Inert gas fusion-capillary trap condensation method was applied for the determination of oxygen in iron, steel and ferrous alloys.

The flow rate of argon used for the carrier gas. was controlled to $250 \mathrm{~mL} / \mathrm{min}$ in each case and degassing was carried out at $2400^{\circ} \mathrm{C}$ for about $30 \mathrm{~min}$, until the blank value became less than $5 \gamma /$ min as oxygen.

In the case of iron or steel, the reaction temperature for the extraction of gas from sample was controlled to $1700^{\circ} \mathrm{C}$. For the analysis of $\mathrm{Fe}-\mathrm{Cr}$ alloy, the extraction temperature was controlled to $1950 \pm 50^{\circ} \mathrm{C}$, without using any metal baths.

The determination of oxygen in Fe-Mn alloy, which has never been done by vacuum fusion method, was succeeded by the proposed method by using tin as bath and controlling the reaction temperature at $1650^{\circ} \mathrm{C}$. In this case, however, fresh tin must be added every time when each sample was charged for the analysis.

The results of oxygen analysis by using this method gave a very good reproducibility.

(Received August 3, 1963)

\section{I. 緒}

鉄鋼中酸素の分析法として一般に行なわれている真空溶 融法は，すぐれた方法ではあるが，高真空を扱うため操作 は繁雑で, 結果を得るまでに長時間を要し, かつ多量の水 銀を使用するので，その中毒の危険性がしばしば報告され ている(1). 近来諸外国でキ+リヤーガスを用いる方法が行 なわれているが (2) (5)，このいわゆる不活性ガス溶融法は 常圧のもとで行ならため分析操作は簡易で, かつ真空溶融 法とことなり，試料の投入は極めて容易で迅速に結果を得 ることができる．また，水銀の使用量もわゔかでその中毒 の危険性は全くない，当所では測定法に凝縮気化法を用い たアルゴン送気加熱装置により，鉄鋼和よび鉄合金等の酸 素の定量法の検討を行なつたのでその結果を報告する.

** 東北大学金属材料研究所 (The Research Institute for Iron, Steel and Other Metals, Tohoku University, Sendai)

*** 東芝電興株式会社 (Toshiba Denkô Co., Ltd., Tokyo)

* 1962 年 10 月本会広島大会に発表

（1）学振 19 委鉄鋼ガス分析協議会資料, 6773 他.

(2) W.G.Smiley: Anal.Chem., 27 (1955) ,1098.

(3) P. Elbling and G. W. Gowand: ibid, $32(1960)$, 1610.

(4) C.V.Banks, J. W. O'laughlin and G. J. Kumin: ibid , 1613 .

(5) S.Kallman and F.Collier: ibid,1616.

\section{II. 装}

使用した装置は Fig. 1 に示す通りであるが，各部の接 続は銅管およびガラス管を，またガラス管相互の接続は球

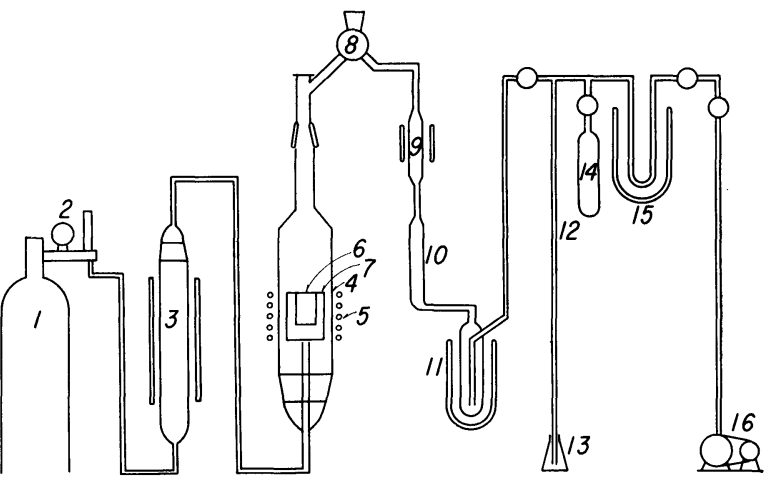

Fig.1 Apparatus for oxygen analysis by capillary trap condensation method.

1. Argon, 2. Regulator with flowmeter, 3. Sponge titanium for purification of argon 4. Quartz reaction tube, 5 . High frequency electric furnace, 6. Graphite crucible, 7. Quartz crucible, 8. Three way stop cock for sample inlet, 9. $\mathrm{I}_{2} \mathrm{O}_{5}, 10 . \mathrm{Na}_{2} \mathrm{~S}_{2} \mathrm{O}_{3}, 11$. Trap (cool with dry-ice and alcohol), 12. Manometer, 13. Mercury pool, 14. Expansion bulb, 15. Trap for $\mathrm{CO}_{2}$ (cool with liq. air), 16 . Rotary pump.

面すり合せを用いた.な挌試料投入コックは Fig.2 に示す ような構造で, 最大長さ $23 \mathrm{~mm}$, 径 $6 \mathrm{~mm}$ の試料を投入 
することができる，石英反応管の両端はすり合せのキヤッ プをつけ，上部のキャップはすり合せの部分を水冷し，下

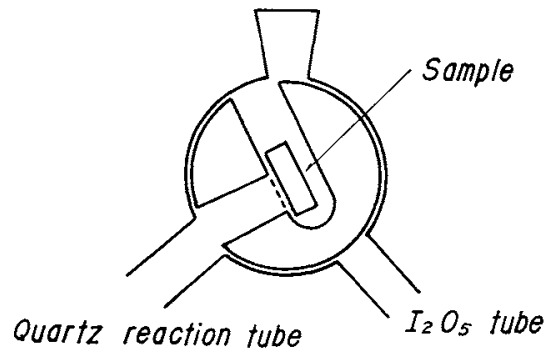

Fig.2 Three-way stop min とした. 鉄鍓の分析温度については Table 2 に示す 通り $1800^{\circ} \mathrm{C}$ 以上の高温ではかえつてやや低值を示す傾向

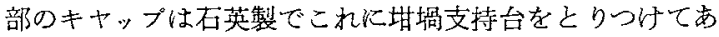
る・アルゴンガスの精製は $500^{\circ} \mathrm{C} に$ 加熱したスポンジチ タンを通して行なつた。な挆使用したアルゴンガスは，日 本酸素製カントパック用高純度 $(99.99 \%)$ のものである. 試料溶融用の黒鉛塔城は日本カーボン製で外径 $20 \mathrm{~mm}$, 内径 $14 \mathrm{~mm}$, 深さ $25 \mathrm{~mm}$, 底の厚さ $10 \mathrm{~mm}$ のもので,

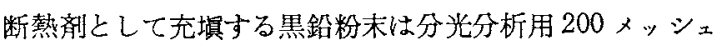
のあのを用いた，試料中の酸素の反応により発生する一酸 化炭素の酸化には， $150^{\circ} \mathrm{C}$ に加熱した五酸化沃素を用い， 遊離した沃素は，チ才硫酸ナトリウムで吸収し，ドライア イスアルコールトラップにより脱水する，炭酸ガスは液体 空気以より捕捉する。なおガス压の測定は，キャピラリマ ノメーターを用いた (Fig.1-12).

\section{III. 分析条件の決定}

黒鉛剒墧を黒鉛粉末を夼填した石英もしくはアルミナ畤 融に入れ，石英反応管内に插入する．脱がスを加熱温度 $2400^{\circ} \mathrm{C}$ ，アルゴン流量 $500 \mathrm{~mL} / \mathrm{min}$ で $30 \mathrm{~min}$ 行なつた 後, 試料の分析を行なう。まず, 分析の際の、アルゴン流 量, 反応温度, ガス捕集時間などの各条件について検討を 行なつた、その結果を Table 1 执よび 2 に示す. Table 1 からわかるよ5に，アルゴン流量は $200 〜 400 \mathrm{~mL}$ の間で 分析值に著しい差異は認められなかつたが，流量が多くな

Table 1 The relation between argon flow rate and the time required for gas collection.

\begin{tabular}{c|c|c|c|c}
\hline $\operatorname{Tim}(\min )$ & 5 & 10 & 15 & $\begin{array}{c}\text { V.F. } \\
\text { method }\end{array}$ \\
$\begin{array}{c}\text { Ar flow rate } \\
\mathrm{mL} / \mathrm{min}\end{array}$ & & & & \\
\hline $\begin{array}{c}200 \sim 250 \\
250 \sim 300 \\
350 \sim 400\end{array}$ & $0.10 \%$ & $0.11 \%$ & $0.11 \%$ & $0.11 \%$ \\
\hline
\end{tabular}

Sample: pure iron $0.7 \sim 0.8 \mathrm{~g}$

Temp. for gas extraction: $1700^{\circ} \mathrm{C}$

ると空赛験值が増大と，その変動が大きくなることが考え られたので流量虫 $250 \mathrm{~mL} / \mathrm{min}$ とし，ガス捕集時間は 10

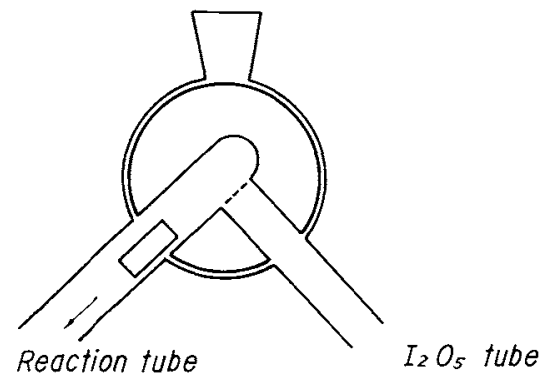

Reaction tube

$\mathrm{I}_{2} \mathrm{O}_{5}$ tube

Table 2 Influence of operating temperature.

\begin{tabular}{|c|c|c|c|}
\hline Sample & ${ }_{1700^{\circ} \mathrm{C}}$ & $\begin{array}{l}1800^{\circ} \\
1900^{\circ} \mathrm{C}\end{array}$ & V.F.method \\
\hline $\begin{array}{c}\text { Pure iron } \\
\text { No. } 1\end{array}$ & $\begin{array}{l}0.100 \% \\
0.098 \% \\
0.100 \%\end{array}$ & $\begin{array}{l}0.096 \% \\
0.096 \% \\
0.094 \%\end{array}$ & $0.099 \%$ \\
\hline $\begin{array}{c}\text { Pure iron } \\
\text { No. } 2\end{array}$ & $\begin{array}{l}0.108 \% \\
0.107 \%\end{array}$ & $\begin{array}{l}0.102 \% \\
0.101 \%\end{array}$ & $0.108 \%$ \\
\hline
\end{tabular}

Sample taken: $0.7 \sim 0.8 \mathrm{~g}$

Ar flow rate: $250 \mathrm{~mL} / \mathrm{min}$

Gas collection time: $10 \mathrm{~min}$

がみられた. 以上の結果から分析操作を次の通り決定し た.すなわち，脱がスを行なつた後加熱温度を $1700^{\circ} \mathrm{C}$ と し，アルゴン流量を $250 \mathrm{~mL} / \mathrm{min}$ とする. 試料投入コック を試料分析の昜合と同じ状態にして $10 \mathrm{~min}$ の空実験値を 澌定する、空実験值が充分に少なく（数 $r / \mathrm{min}$ 程度）なつ たことを確めたならば, 試料をコック中に入れ，数秒間フ

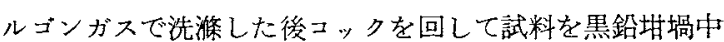

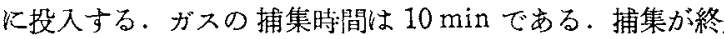
れば゙測定部のコックを切り換え湘定部を真空とし，液体空 気のトラップをとり温めて捕捉した炭酸ガスを気化させ， そのガス庄をマノメーターで読を、マノメーターの読みか らの酸素量の計算は次式による。

$$
\begin{aligned}
& O_{g}=8.56 \times 10^{-7}\left(V x+S \frac{x^{2}}{.10}\right) \\
& x=マ \text { メーターの読み } \mathrm{mm} \\
& V=\text { 测定部内容積 } \mathrm{cc}
\end{aligned}
$$

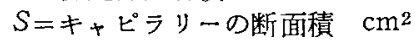

\section{IV. 鉄 銅 分析 結 果}

数種の鉄鋼試料を，以上の操作で分析した結果を Table 3 に示すが，真空溶融法とよく一致した值を得た。なお， N.B.S.酸素標集試料を分析した結果を Table 4 K示す. これは厚さ $5 \sim 6 \mathrm{~mm}$ の円板状試料を図に示すよ5に，1片 が 1 2 g 9 9の小片に切断して，その各るを分析した 結果である、各くの值にはとくに中央部に大きな偏析がみ 
られるものがあるが, 全部の平均值は標準值と略く一致し た値を与えている。

Table 3 The results of the determination of oxygen in iron and steel samples.

\begin{tabular}{l|c|c|c}
\hline \multicolumn{1}{c|}{ Sample } & $\begin{array}{c}\text { Sample } \\
\text { weight } \\
\text { taken }(\mathrm{g})\end{array}$ & \begin{tabular}{c} 
Oxygen determined \\
\cline { 3 - 4 }$(\%)$
\end{tabular} \\
\cline { 3 - 5 } & $\begin{array}{c}\text { Proposed } \\
\text { method }\end{array}$ & $\begin{array}{c}\text { V.F. } \\
\text { method }\end{array}$ \\
\hline pure iron No. 33820 & 4.810 & 0.0067 & 0.0065 \\
pure iron No. 33821 & 1.065 & 0.027 & 0.029 \\
pure iron No. 34829 & 1.434 & 0.056 & 0.056 \\
carbon steel & 4.835 & 0.0068 & 0.0071 \\
mild steel & 2.105 & 0.0067 & 0.0066 \\
\hline
\end{tabular}

結果からわかるよ を用いないと定量值が低く， $1900^{\circ} \mathrm{C}$ 以上では 鉄浴の有無 にかかわらず一致した値を与えた。さらに高温の $2100^{\circ} \mathrm{C}$ に拈いても, $1900^{\circ} \mathrm{C}$ の場合と一致した結果が得られた。 以上の結果よりフェロクロム中の酸素は, 分析温度 $1950^{\circ}$ $\pm 50^{\circ} \mathrm{C}$ で鉄浴を使用することなく充分に定量し得ること がわかつた．次にフェロマンガンについて検討を試みた。 マンガンは高温で蒸発しやすく，かつその蒸着膜が発生し たガスを吸着して低值を与えるため，真空溶融法ではマン ガンの多い試料中の酸素を連続的に定量することは不可能 とされている。しかし，常圧に近い状態で行ならこのアル

Table 4 The results of the determination of oxygen in NBS standard samples.

\begin{tabular}{r|c|c|c|c|c|c|c|c|c|c|c}
\hline Sample & 1 & 2 & 3 & 4 & 5 & 6 & 7 & 8 & 9 & Av. & STD value \\
\hline 1040A & 0.0120 & 0.0160 & 0.0143 & 0.0125 & 0.0328 & 0.0192 & 0.0119 & 0.0135 & 0.0138 & 0.0162 & 0.018 \\
$\mathrm{~B}$ & 0.0111 & 0.0177 & 0.0129 & 0.0150 & 0.0324 & 0.0181 & 0.0140 & 0.0142 & 0.0158 & 0.0168 & \\
\hline $1041 \mathrm{~A}$ & 0.0163 & 0.0165 & 0.0177 & 0.0139 & 0.0361 & 0.0152 & 0.0176 & 0.0150 & 0.0160 & 0.0182 & 0.017 \\
$\mathrm{~B}$ & 0.0168 & 0.0160 & 0.0172 & 0.0133 & 0.0347 & 0.0146 & 0.0166 & 0.0152 & 0.0188 & 0.0181 & \\
\hline 1044 A & 0.0118 & 0.0095 & 0.0118 & 0.0097 & 0.0109 & 0.0101 & 0.0116 & 0.0106 & 0.0121 & 0.0108 & 0.009 \\
$\mathrm{~B}$ & 0.0118 & 0.0108 & 0.0126 & 0.0108 & 0.0132 & 0.0116 & 0.0099 & 0.0108 & 0.0115 & 0.0114 & \\
\hline 1045 A & 0.0088 & 0.0073 & 0.0089 & 0.0069 & 0.0072 & 0.0084 & 0.0073 & 0.0076 & 0.0077 & 0.0078 & 0.007 \\
$\mathrm{~B}$ & 0.0076 & 0.0072 & 0.0072 & 0.0072 & 0.0077 & 0.0069 & 0.0067 & 0.0068 & 0.0063 & 0.0072 & 0.007 \\
\hline 1047 A & 0.0131 & 0.0163 & 0.0127 & 0.0159 & 0.0363 & 0.0159 & 0.0130 & 0.0176 & 0.0140 & 0.0172 & 0.017 \\
$\mathrm{~B}$ & 0.0133 & 0.0160 & 0.0130 & 0.0133 & 0.0344 & 0.0161 & 0.0138 & 0.0190 & 0.0130 & 0.0170 & 0.017 \\
\hline
\end{tabular}

Each number in the table shows the position of the sample taken from original N.B.S. sample given in Fig.3.

\section{V. 鉄 合 金 の 分 析 結 果}

以上の実験結果より，アルゴン送気加熱法は鉄鋼中の酸 素分析法として満足すべきものであることがわかつたの でこれによる鉄合金の酸素分析法を検討した。まずフェ ロクロムについて実験した結果を Table 5 に示す．この

Table 5 The investigation for the reaction temperature for the analysis of oxygen in $\mathrm{Fe}-\mathrm{Cr}$ alloy.

\begin{tabular}{l|lll|l}
\hline \hline \multirow{2}{*}{$\begin{array}{c}\text { Reaction } \\
\text { temp. }\left({ }^{\circ} \mathrm{C}\right)\end{array}$} & \multicolumn{4}{|c}{ Oxygen determined $(\%)$} \\
\cline { 2 - 5 } & & & & Average \\
\hline \multirow{3}{*}{$1700 \sim 1800$} & 0.044 & 0.048 & 0.044 & 0.044 \\
\cline { 2 - 5 } & 0.044 & 0.044 & 0.042 & \\
\hline \multirow{3}{*}{$1900 \sim 2000$} & $0.048^{*}$ & $0.051^{*}$ & $0.050^{*}$ \\
\hline \multirow{2}{*}{$2000 \sim 2100$} & 0.050 & 0.050 & 0.048 & 0.048 \\
& 0.046 & 0.048 & 0.047 & \\
\hline
\end{tabular}

Sample weight taken: $1.5 \sim 0.5 \mathrm{~g}$

* Iron bath was used.

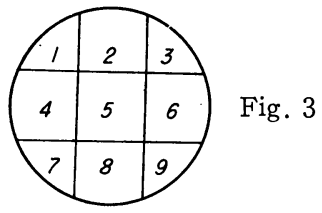

ゴン送気加熱法ではある程度その蒸発速度を抑制し得ると 考えられる.そこでまず鉄鋼試料の分析の場合と同じ条件 に拈いて，金属浴を用いずに塊状試料を投入して実験を行 なつてみた。その結果は, 分析開始值前の空実験値が，10 $\min$ で $42.8 \gamma$ であつたものがフェロマンガン試料 $0.46 \mathrm{~g}$ を投入して分析すると，その直後は $10 \mathrm{~min} て ゙ ~ 9.0 \gamma$ とな り,さらに試料 $0.68 \mathrm{~g}$ を投入分析した直後の空実験値は $10 \min$ で $5.6 \gamma$ と極端に減少し, 試料の 全酸素量も 0.46 $\mathrm{g}$ の試料で $57.4 \gamma, 0.68 \mathrm{~g}$ の試料で $44.2 \gamma$ と減少して, マ ンガンの蒸着による影響はやはり抑制できないことを示し た. そこでマンガン蒸着膜の影響を防ぐ効果があるとされ る錫を試料の約 10 倍量用い, 黒鉛坩堝中で溶融脱ガス後, 試料を投入して酸素定量を行なつたところ Table 6 に示 されるよ5に，試料毎に錫を加えて常に新しい浴を使用す ることにより，連続的に定量を行なつても定量值に大きな 差は認められなかつた。なお，このときの空実験値は分析 直前直後とも $10 \mathrm{~min}$ で, $25.8 \gamma \sim 21.2 \gamma$ の間で $(2 \sim 3 \gamma /$ 
min) ほとんど差がなからた、フェロマンガン中の酸素の 定量は標準とすべき值を真空溶融法などによつて得ること

Table 6 The results of the determination of oxygen in Fe-Mn alloys by tin-bath fusion.

\begin{tabular}{c|c|c|c|c}
\hline Sample & $\begin{array}{c}\text { Weight of } \\
\text { sample } \\
\text { taken (g) }\end{array}$ & $\begin{array}{c}\text { Tin } \\
\text { added }\end{array}$ & $\begin{array}{c}\text { Oxygen (\%) } \\
\text { Deter- } \\
\text { mined }\end{array}$ & Average \\
\hline \multirow{3}{*}{ MC-Fe-Mn II A } & 0.4968 & 5.0 & 0.014 & \\
& 0.7494 & 7.0 & 0.012 & 0.012 \\
& 0.5110 & 5.0 & 0.010 & 0.012 \\
\hline & 0.7867 & 5.0 & 0.011 & \\
HC-Fe-Mn II B & 0.3610 & 8.0 & 0.146 & \\
& 0.2860 & & 0.128 & \multirow{2}{*}{0.132} \\
& 0.3701 & 4.0 & 0.138 & 0.132 \\
& 0.3959 & 4.0 & 0.128 & \\
\hline
\end{tabular}

が不可能であるが，アルゴンガス送気加熱法に和いては Table 6 の結果に示されたよ
よつて酸素含有量の少ない場合も，多い場合も略々一致し た值を示すので，本法によつて定量可能ですると考えられ 子.

\section{VI. 結言}

凝縮気化法を測定法とするアルゴン送気加熱比よる酸素 定量装置を組立て，これにより鉄鋼劣よび二,三の鉄合金 の酸素定量法の検討安行なつた。その結果，鉄鋼について

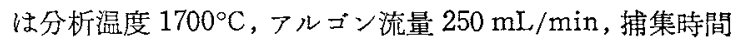
$10 \mathrm{~min} て ゙$ 真空溶融法とよく一致した值を得ることができ， またN.B.S. 酸素標準試料注いても良好な結果を得るこ とができた。

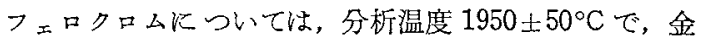
属浴を用いることなく定量できる条件を見出し，またフェ ロマンガンについては，錫浴を用いることによつて連続定 量が可能であることを見出した。 